\title{
Protein tyrosine kinases in Schistosoma mansoni
}

\section{Diana Bahia/ ${ }^{+}$, Luiza Freire Andrade*, Fernanda Ludolf*, Renato Arruda Mortara**, Guilherme Oliveira/*}

\author{
Centro de Pesquisas René Rachou-Fiocruz, Av. Augusto de Lima 1715, 30190-002 Belo Horizonte, MG, Brasil \\ *Programa de Pós-Graduação e Pesquisa, Santa Casa de Misericórdia de Belo Horizonte, Belo Horizonte, MG, Brasil \\ **Escola Paulista de Medicina, Unifesp, São Paulo, SP, Brasil
}

The identification and description of signal transduction molecules and mechanisms are essential to elucidate Schistosoma mansoni host-parasite interactions and parasite biology. This mini review focuses on recent advancements in the study of signalling molecules and transduction mechanisms in $\mathrm{S}$. mansoni, drawing special attention to the recently identified and characterised protein tyrosine kinases of $\mathrm{S}$. mansoni.

Key words: signal transduction - protein kinase - schistosoma - tyrosine kinase

The identification and characterisation of signal transduction molecules and mechanisms are essential to elucidate Schistosoma mansoni host-parasite interactions and parasite biology. Protein tyrosine kinases (PTKs) are important molecules for intra- and inter-cellular communication as well as for survival in eukaryotes, playing a major role in signal transduction processes (Hanks et al. 1988). PTKs also participate in cellular mechanisms that control several biological processes such as adhesion, cytoskeleton reorganisation, and migration. These proteins are also known to be involved in developmental and differentiation processes of cells. Therefore, the study of PTKs may unveil strategies that can be used for identifying new candidate drug targets.

Phosphorylation of protein substrates catalysed by kinases is an essential mechanism by which important intracellular and extracellular signals are transmitted throughout the cell and to the nucleus (Cheetham 2004). During kinase catalysis, the $\gamma$-phosphate group from ATP is transferred to the protein substrate, thereby changing the substrate properties (e.g. its structure, location or its activity as enzyme) (Manning et al. 2002a).

The recent success in cancer treatment that includes specific tyrosine kinase inhibitors strongly validates the clinical relevance of basic research on tyrosine phosphorylation. Functional profiling of the tyrosine phosphoproteome is likely to lead to the identification of novel targets for drug discovery, providing a basis for novel molecular target approaches (Machida et al. 2003). Many of the 500 or so identified human protein kinases are attractive drug targets to treat cancer, inflammation processes and autoimmune diseases.

Financial support: Fapemig (DB CBB-174/02)

${ }^{+}$Corresponding author and $\mathrm{CNPq}$ fellow. Present address: Departamento de Genética, ESALQ, USP, Av. Pádua Dias 11, 13400-970 Piracicaba, SP, Brasil.

E-mail: dianabahia@hotmail.com.

Received 25 May 2006

Accepted 26 June 2006

\section{PTKs}

PTKs comprise proteins found in multicellular organisms (Neet \& Hunter 1996). PTKs may be found (i) anchored in the cell membrane, acting as receptors, (ii) free in the cytoplasm, participating in signalling cascades, and (iii) in the nucleus, directly associated with gene activation processes. PTK catalytic domain activation results from the interaction with other signalling proteins, which allows specifically signalling propagation. There is no evidence of PTK in yeast. However, 49 from 239 Drosophila melanogaster PKs and 105 out of 454 Caenorhabditis elegans PKs have been classified as PTKs (Manning et al. 2002a). There are two major classes of PTKs, receptor tyrosine kinases (RTKs) and non-receptor tyrosine kinases, also named cytoplasmic or cellular tyrosine kinases (NRTKs) (Neet \& Hunter 1996).

Receptor tyrosine kinases (RTKs) - RTKs contain three distinct regions: an extracellular binding domain, a transmembrane helix, and a cytoplasmatic domain that contains the kinase activity (Hubbard \& Till 2000). RTK activation is generally triggered by the interaction of a ligand with a specific biding site on the receptor extracellular domain. Following RTK stimulation at the extracellular site, the catalytic domain on the cytoplasmic side of membrane is activated by the dimerisation of the receptor, leading to autophosphorylation (Alberts et al. 1994) and then to the activation of kinase activity, providing a new biding site for intracellular adapter molecules.

RTK families show diversified extracellular domains (Heldin 1996). The first protein receptor described as being protein kinase tyrosine-specific was the epidermal growth factor receptor (EGFr) (Yarden \& Ullrich 1988). However, there are growth and differentiation factor receptors that also belong to RTKs.

Non-RTKs (NRTK) - NRTKs are a set of intracellular signalling proteins that has been identified as being able to interact with PTK phosphotyrosine (Neet \& Hunter 1996). Although intracellular signalling proteins that bind to activated PTK phosphotyrosine residues have various functions and structures, they generally share highly conserved non-catalytic domains, known as $\mathrm{SH} 2$ and $\mathrm{SH} 3$. One of the main features of NRTK is the presence of the 
SH2 domain. SH2 domains are small protein modules that bind specifically to tyrosine-phosphorylated peptides. There are more than $100 \mathrm{SH} 2$ domains in the human genome, and different $\mathrm{SH} 2$ domains bind to different classes of tyrosine-phosphorylated ligands. These domains play a critical role in the propagation of signals in the cell, mediating the relocation and complex formation of proteins in response to changes in tyrosine phosphorylation (Machida et al. 2003).

\section{Protein kinases and schistosome biology}

Animal cells normally divide when stimulated by growth factors, which are generally produced by other cells and act via RTKs. Given that mutations leading to amino acid substitutions on protein kinases are common in cancer, diabetes and other diseases, a better understanding on how such enzymes regulate a wide range of functions may enable further therapeutic interventions (Plowman et al. 1999). Further knowledge on PTKs may provide new strategies for drug development, an approach intensively pursued in cancer research (Traxler 2003, Harari 2004). As sensing and responding to the environment are essential in the complex life cycle of schistosomes, the knowledge gained by studying signal transduction proteins and their mechanisms will be important for understanding the biology of the organism.

\section{S. mansoni proteins involved in signal transduction}

It is now clear that the ability of S. mansoni to survive for decades in the blood-stream of its host and the sexual maturation of the female that depends on a close contact with the male are processes that require molecular communication (Schussler et al. 1997, Kunz 2001, Kapp et al. 2004).

Recently, a number of signalling molecules have been identified and cloned in schistosomes, including transmembrane and cellular receptors (Table I).

Some of the signalling proteins seem to be involved with the SmRK (S. mansoni receptor kinase) signalling pathway. SmRK is a divergent member of the serin/ threonin kinase TGF- $\beta$ receptor (transforming growth factor beta receptor family), possibly participating in the host response to growth factors such as: cell migration, differentiation, adhesion and apoptosis. SmRK1 is a surface membrane receptor serine/threonine (Davies et al. 1998) belonging to the $S$. mansoni TGF- $\beta$ superfamily that may be important in mediating host-parasite interactions associated with parasite development. Sm14-3-3E is a cytoplasmatic protein associated with TGF- $\beta$ (McGonigle et al. 2001a). The overexpression of Sm14-3-3a leads to increased TGF- $\beta$ signalling, whereas eIF $2 \alpha$ (eukaryotic initiation factor 2 alpha subunit) leads to TGF- $\beta$ inhibition (McGonigle et al. 2002). Smads are able to interact with receptor molecules carrying the message to the nucleus. Both Smads (SmSmad1 and SmSmad2) and SmRK1 are found in the same developmental stages (lung stage and adult parasites). SmSmad2 interacts with SmRK1, while SmSmad4 interacts with SmSmad1 and SmSmad2, besides phosphorylating Erk1/2 (kinase regulated by extracellular signal) (Beall et al. 2000, Beall \& Pearce 2001, Osman et al. 2001, 2004). FKBP12 influences a variety of signal trans-
TABLE I

Signalling molecules identified in Schistosoma mansoni

\begin{tabular}{ll}
\hline Protein & References \\
\hline CaBPs & Siddiqui et al. 1991 \\
MAP kinase & Schussler et al. 1997 \\
GAP & Schussler et al. 1997 \\
HSF & Lantner et al. 1998 \\
SmRK1/SmTbRI & Davies et al. 1998 \\
SmRXR1 & Freebern et al. 1999a \\
SmRXR2 & Freebern et al. 1999b \\
SmRas1 & Kampkotter et al. 1999, \\
Sh-TOR & Osman et al. 1999 \\
SmSmad1 & Inal 1999 \\
SmMAK16 & Beall et al. 2000 \\
SmSmad2 & Milhon et al. 2000 \\
Sm14-3-3e & Beall et al. 2000, \\
SMA3 & Osman et al. 2001 \\
SIP & McGonigle et al. 2001a \\
SmFTZ-F1 & Da'dara et al. 2001 \\
eIF2a & McGonigle et al. 2001b \\
SmRhoI & De Mendonça et al. 2002 \\
SmSmad4 & McGonigle et al. 2002 \\
SmRK2/SmTbRII & Santos et al. 2002, \\
SmFKBP12 & Vermeire et al. 2003 \\
SchP2X & Osman et al. 2004 \\
SmPKC1 & Forrester et al. 2004 \\
\hline
\end{tabular}

duction pathways that regulate cell division, differentiation, and ion homeostasis. Among these, TGF- $\beta$ signalling and calcineurin $(\mathrm{CN})$ phosphatase activity are modulated by FKBP 12 via binding to TGF- $\beta$ family type I receptors (TGFbR-I) or to the $\mathrm{CN}$ subunit A, respectively (Chen et al. 1997). The S. mansoni FKBP12 homologue (SmFKBP12) is a direct partner of SmRK1 and both are present and interact in the female gonads (Knobloch et al. 2004).

Other signalling proteins found in S. mansoni participate in several different pathways and functions. SmPKC1 has been recently described by our group as the first $\beta 1$ type protein kinase C identified in S. mansoni. Immunolocalisation studies indicated that SmPKC1 was strongly associated with the ridge cyton and excretory vesicles in sporocysts, while in skin-stage schistosomula, SmPKC1 was clearly expressed in the acetabular gland, tegument, and duct (Bahia et al. 2006a). SmMAK16 contains a nuclear signalling portion and a site for CK2 (casein kinase 2) phosphorylation, being related to the biogenesis of the ribosome 60S subunit as well as to the cell cycle with higher expression levels in female worms (Milhon et al. 2000). SmRXR are nuclear receptors and gene transcription activators. The SmRXR gene is constitutively expressed and thus must play multiple roles throughout the schistosome life cycle. SmRXR is located in vitellinic cells, and may play a role in the activation of the eggshell p14 gene precursor. (Freebern et al. 1999a,b, Fantappié et al. 2001). SmFTZF1 is another nuclear receptor with a highly conserved DNA binding domain, related with developmental and sexual differentiation (de Mendonça et al. 2002). 
SchP2X is related to the ATP ionic channel opening (Agboh et al. 2004). SmRhoI (Santos et al. 2002, Vermeire et al. 2003) is a GTPase that possibly participates in the cytoskeleton organisation, gene transcription, cell cycle and membrane transport and is expressed at higher levels in female worms (Vermeire et al. 2003). SMA3 is a Ca-ATPase homologue found in the adult tegument, suggesting that SMA3 functions to help control Ca homeostasis within the tegument and may play a role in signal transduction at the host-parasite interface (Da'dara et al. 2001).

\section{PTKs identified in S. mansoni}

Very few PTKs have been identified and characterised in S. mansoni: three of them are RTKs (SmRTK-1, SmIR-1, SER), and four are NRTKs (TK5, TK4, TK3, SmFes), (Table II).

SmRTK1 is a membrane protein with an extracellular binding domain similar to several protein domains that share the Venus Flytap-VFT structure and the cytoplasmatic TK domain, which is similar to the insulin receptor (IR) catalytic domain. The SmRTK1 gene is expressed throughout all developmental stages. In males, it is preferably found in parenchyma cells. In females, an intense labelling was associated with ovocytes present in the ovary and in the ovary duct. SmRTK1 is believed to constitute an original GABA-activated RTK, which is involved in pheromone recognition, necessary for the development of the female ovaries (Vicogne et al. 2003). SmRTK1 was localised in sporocysts. The preferential localisation of SmRTK1 in sporocysts germinal cells and ovocytes could point to a role in schistosome growth and differentiation.

SmIR-1 is a tyrosine kinase similar to the family members of IR. It has all the features of IR with a conserved ligand-binding domain. Immunohistochemical studies have shown that SmIR-1 is mainly expressed at the basal membrane level of the tegument in adult worms (Dissous et al. 2006, Khayath et al. unpublished results). It might play a role in glucose uptake regulation.

SER is an epithelial growth factor receptor that contains a TK domain homologous to the TK domain of the erbB family. The gene is translated into a $170 \mathrm{kDa}$ protein that contains a signal peptide, a cystein-enriched extracellular domain, a transmembrane hydrophobic sequence, and an intracellular TK domain. The SER protein is present in cercariae and, more strongly, in adult worm muscles (Ramachandran et al. 1996), suggesting that it could participate in muscle development and function. The genes produce three variant transcripts, resulting from SER alternative splicing (Shoemaker et al. 1992). SER seems to be activated by vertebrate EGF ligands besides activating ERK signalling, suggesting a conservation of the EGFR function in Schistosoma (Vicogne et al. 2004).

The NRTKs identified in $S$. mansoni have common domains, as shown in Fig. 1. TK5 and TK3 (Fig. 1, Table II) are NRTK orthologues to the Src family. They contain SH3 and SH2 domains followed by a C-terminal catalytic domain with a tyrosine kinase activity. TK5 is the first Fyn subfamily identified in invertebrates (Kapp et al. 2001). TK3 is a single-copy gene and it codes for a $71 \mathrm{kDa}$ protein expressed in adult worms of both sexes, predominantly in the reproductive organs. Its enzymatic activity

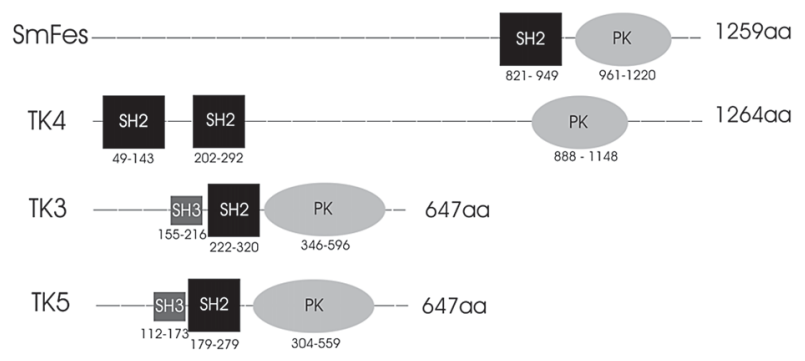

Fig. 1: structural organization of the non-receptor tyrosine kinases (NRTKs) identified in Schistosoma mansoni - SmFes, TK3, TK4, and TK5. SmFes exhibits the characteristic features of Fes/fps protein tyrosine kinases (PTK) family containing a $\mathrm{SH} 2$ and protein tyrosine kinase catalytic domain signatures. TK3 and TK5 are orthologues to the Src family kinase. As expected for members of the Src family, TK5 and TK3 contain the SH3 domain, the SH2 domain and the catalytic tyrosine kinase domain. The N-terminal myristylation motif in TK3 and TK5 is not indicated. TK4 is a Syk family kinase containing a catalytic TK domain and two SH2 domains. Numbers underneath the boxes indicate the position of aminoacids. Numbers on the right indicate the total number of aminoacids.

was experimentally demonstrated in a heterologous eukaryote cell culture system, which was able to phosphorylate p130Cas, a protein closely related to proteins involved in focal adhesion and cytoeskletal organization (Kapp et al. 2004). Most Src family kinases contain an Nterminal Met-Gly-Cys consensus sequence that undergoes dual acylation with myristate or palmitate after methionine removal (Pellman et al. 1985, Resh 1994). Although this has not been yet experimentally demonstrated, both TK3 and TK5 presumabily have an N-terminal myristylation motif, responsible for targeting the Src-related proteins to cellular membranes.

TK4 (Fig. 1, Table II) is a NRTK orthologue to the Syk family. TK4 contains two SH2 domains and one tyrosine kinase domain. It is transcribed in maturing and mature adult stages, as well as in larval stages miracidia and cercariae. The presence of TK4 in oocysts and spermatocytes suggests that this protein plays a role in germinative cell development. However, there are no report in literature on the involvement of Syk in gonad differentiation (Knobloch et al. 2002).

Our group has previously identified and characterised the molecular structure of a new PTK in S. mansoni, SmFes (Fig. 1, Table II, Ludolf et al. unpublished results). SmFes exhibits the characteristic features of Fes/fps protein tyrosine kinases subfamily, a coiled-coil region, $\mathrm{SH} 2$ and protein tyrosine kinase catalytic domain signatures, but lacks the FCH amino-terminal domain. It is the first member of Fes subfamily described in helminths. SmFes expression was detected by immunolocalisation in both miracidia and skin-stage schistosomula (Bahia et al. unpublished results). In miracidia, SmFes is expressed in the terebratorium (Fig. 2A), whereas in schistosomula it is localized in the oral sucker, acetabular glands, and tegument (Fig. 2B). In cercariae, an expression pattern similar to schistosomula was observed (not shown). Due to functions attributed to both acetabular glands, oral sucker 
TABLE II

Protein tyrosine kinases (receptor tyrosine kinases-RTKs and non-receptor tyrosine kinases- NRTKs) identified in Schistosoma mansoni

\begin{tabular}{lllll}
\hline & Family & Function & Localisation & References \\
\hline SER & EGFR & $\begin{array}{l}\text { Participates in schistosome } \\
\text { signal transduction, perhaps } \\
\text { (170kDa) }\end{array}$ & $\begin{array}{l}\text { Predominantly in the muscle } \\
\text { of adult male and female }\end{array}$ & Ramachandran et al. 1996 \\
GenBank & & $\begin{array}{l}\text { worms } \\
\text { M86396 }\end{array}$ & & or function
\end{tabular}

M86396

SmRTK1 Insulin Probably with a role in male-

$(172 \mathrm{kDa}) \quad$ receptors

GenBank

AF101194

\begin{tabular}{|c|c|c|}
\hline $\begin{array}{l}\text { SmIR-1 } \\
(170 \mathrm{kDa}) \\
\text { GenBank } \\
\text { AF314754 }\end{array}$ & $\begin{array}{l}\text { Insulin } \\
\text { receptors }\end{array}$ & $\begin{array}{l}\text { Possible role in the regulation } \\
\text { of the uptake of glucose via the } \\
\text { activity of SGTP1 and SGTP4 }\end{array}$ \\
\hline $\begin{array}{l}\text { TK3 } \\
(71 \mathrm{kDa}) \\
\text { GenBank } \\
\text { AJ585205 }\end{array}$ & Src & $\begin{array}{l}\text { Seems to play a role in signal } \\
\text { transduction pathways } \\
\text { organising the cytoskeleton in } \\
\text { the gonads of schistosomes }\end{array}$ \\
\hline $\begin{array}{l}\text { TK5 } \\
(73 \mathrm{kDa}) \\
\text { GenBank } \\
\text { AF232691 }\end{array}$ & Src-like & $\begin{array}{l}\text { Seems to play a role during } \\
\text { embryogenesis as well as gut } \\
\text { formation and/or function }\end{array}$ \\
\hline $\begin{array}{l}\text { TK4 } \\
(140 \mathrm{kDa}) \\
\text { GenBank } \\
\text { AJ421472 }\end{array}$ & Syk & $\begin{array}{l}\text { May play a role in germ cell } \\
\text { development }\end{array}$ \\
\hline $\begin{array}{l}\text { SmFes } \\
(143 \mathrm{kDa}) \\
\text { GenBank } \\
\text { AF515706 }\end{array}$ & Fes/Fps & $\begin{array}{l}\text { May play a role in the signal } \\
\text { transduction pathway involved } \\
\text { in the larvae transformation } \\
\text { after penetration into } \\
\text { intermediate and definitive } \\
\text { hosts }\end{array}$ \\
\hline
\end{tabular}

and terebratorium, these findings seem to suggest that SmFes plays a pivotal role in the signal transduction pathway involved in the larvae transformation after penetration into intermediate and definitive hosts.

\section{Presence of PKs in sequenced genomes}

PKs have been characterised not only through traditional biochemical techniques but also by catalytic domain analyses from aminoacid sequences of their primary structure (Hanks et al. 1988). PKs comprise one of the largest families of proteins, which correspond to 1.5 to $2.5 \%$ of eukaryote genes (Manning et al. 2002a). The development of genomic studies has led to the identification of an increasing number of $\mathrm{PK}$ in various animal species.

The genome of $S$. mansoni is currently being assembled and annotated and two large scale transcriptome projects described the majority of the genes of this spe- cies (El Sayed et al. 2004, Oliveira et al. 2004, Oliveira \& Bahia 2004, Verjovski et al. 2004). It is expected that the release of a full analysis of these projects will reveal a large number of proteins related to parasite-environment and parasite-host interactions, among them PTks.

By using C. elegans as model for studies on signal transduction, as it was the first fully sequenced multicellular organism, Pks were grouped into the second biggest family of the protein domains in theses worms, comprising 411 fully sequenced PKs (Plowman et al. 1999). Sequencing of the human genome revealed $518 \mathrm{PK}$ coding genes, $1.7 \%$ of the entire human gene content. Among the $258 \mathrm{PKs}$ analysed, 83 domain types were identified, most of which are found to be closely related to signalling protein interaction domains, e.g., SH2, which recognises and binds to phosphorylated tyrosine residues (Manning et al. 2002b). By comparing kinomes from $S$. cerevisiae (yeast), C. elegans (worm), D. melanogaster (insect) and 


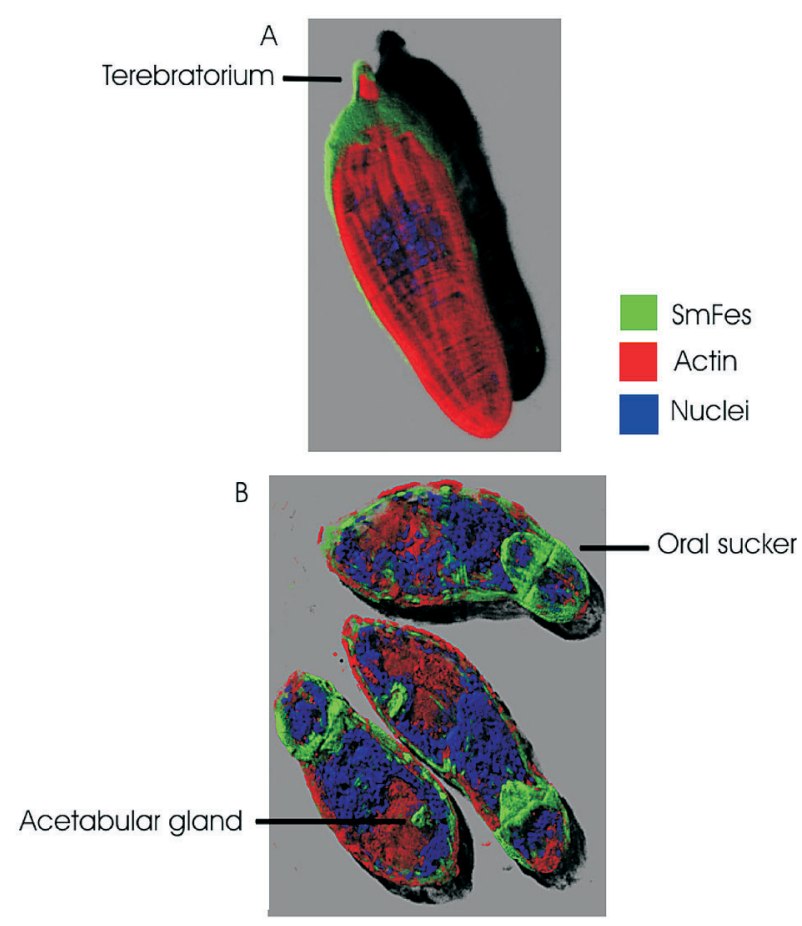

Fig. 2: immunolocalization of SmFes in miracidia and skin-stage schistosomula. Optical sections of confocal images obtained from immunolocalisation of SmFes were tridimensionally projected and renderised. The presence of SmFes (in green) can be observed in terebratorium (miracidia) (A) and in oral sucker and acetabular gland (schistosomula) (B) (unpublished results). Actin (red) and DAPI (blue) labellings were obtained according to Bahia et al. (2006b).

Homo sapiens (mammal), out of 209 subfamilies analysed, 51 proteins were present in the four genomes, 7 were only present in yeast (S. cerevisiae and S. pombe), 15 in $C$. elegans, 13 in $H$. sapiens, and none in D. melanogaster (Manning et al. 2002a).

PKs represent promising drug targets for a number of human and animal diseases. The recent completion of the genomes of three human-infective trypanosomatid protozoa, Leishmania major, Trypanosoma brucei and T. cruzi, has allowed the kinome for each parasite to be defined as 179,156 , and 171 eukaryotic protein kinases, respectively (Naula et al. 2005), that is about one third of the human complement.

Last but not least, several lines of evidence suggest that it is worth pursuing the study of the PK family to identify drug targets for shistosomes. PKs have been shown to be essential for proliferation and/or viability of parasite life-cycle stages that are clinically relevant. As a general rule, PKs having more than $60 \%$ sequence identity over the core catalytic domain have a high probability of being inhibited by the same group of low molecular mass compounds. The corollary is that "there is a higher level of confidence that specific inhibitors can be designed to target protein kinases with $<60 \%$ sequence identity, which is the case for the vast majority of parasite kinomes when compared to that of humans" (Vieth et al. 2004, Naula et al. 2005).

\section{REFERENCES}

Agboh KC, Webb TE, Evans RJ, Ennion SJ 2004. Functional characterisation of a P2X receptor from Schistosoma mansoni.J Biol Chem 279: 41650-41657.

Alberts B, Bray D, Lewis J, Raff M, Roberts K, Watson J 1994. Molecular Biology of the Cell, Garland Publisher, NewYork/London, 1616 pp.

Bahia D, Avelar L, Mortara RA, Khayath N, Yan Y, Noel C, Capron M, Dissous C, Pierce RJ, Oliveira G 2006a. SmPKC1, a new protein kinase C identified in the platyhelminth parasite Schistosoma mansoni. Biochem Biophys Res Commun 345: 1138-1148.

Bahia D, Avelar LGA, Vigorosi F, Cioli D, Oliveira GC, Mortara RA 2006b. The distribution of motor proteins in the muscles and flame cells of the Schistosoma mansoni miracidium and primary sporocyst. Parasitology 133: 1-10.

Beall MJ, Pearce EJ 2001. Human transforming growth factorbeta activates a receptor serine/threonine kinase from the intravascular parasite Schistosoma mansoni. J Biol Chem 276: 31613-31619.

Beall MJ, McGonigle S, Pearce EJ 2000. Functional conservation of Schistosoma mansoni Smads in TGF-beta signalling. Mol Biochem Parasitol 111: 131-142.

Cheetham GMT 2004. Novel protein kinases and molecular mechanisms of Autoinhibition. Science 14: 700-705.

Chen YE, Liu F, Massagué J 1997. Mechanism of TGFbeta receptor inhibition by FKBP12. EMBO J 16: 3866-3876.

Da'dara A, Tsai MH, Tao LF, Marx KA, Shoemaker CB, Harn DA, Skelly PJ 2001. Schistosoma mansoni: molecular characterisation of a tegumental Ca-ATPase (SMA3). Exp Parasitol 98: 215-222.

Davies SJ, Shoemaker CB, Pearce EJ 1998. A divergent member of the transforming growth factor beta receptor family from Schistosoma mansoni is expressed on the parasite surface membrane. J Biol Chem 273: 11234-11240.

DeMendonça RL, Bouton D, Bertin B, Escriva H, Noel C, Vanacker JM, Cornette J, Laudet V, Pierce RJ 2002. A functionally conserved member of the FTZ-F1 nuclear receptor family from Schistosoma mansoni. Eur J Biochem 269: 5700-5711.

Dissous C, Khayath N, Vicogne J, Capron M 2006. Growth factor receptors in helminth parasites: signalling and hostparasite relationships. FEBS Lett 580: 2968-2975.

El Sayed NM, Bartholomeu D, Ivens A, Johnston DA, LoVerde PT 2004. Advances in schistosome genomics. Trends Parasitol 20: 154-157.

Fantappié MR, Freebern WJ, Osman A, LaDuca J, Niles EG, LoVerde PT 2001. Evaluation of Schistosoma mansoni retinoid X receptor (SmRXR1 and SmRXR2) activity and tissue distribution. Mol Biochem Parasitol 115: 87-99.

Forrester SG, Warfel PW, Pearce EJ 2004. Tegumental expression of a novel type II receptor serine/threonine kinase (SmRK2) in Schistosoma mansoni. Mol Biochem Parasitol 136: 149-156.

Freebern WJ, Osman A, Niles EG, Christen L, LoVerde PT 1999a. Identification of a cDNA encoding a retinoid X receptor homologue from Schistosoma mansoni. Evidence for a role in female-specific gene expression. J Biol Chem 274: 4577-4585. 
Freebern WJ, Niles EG, LoVerde PT 1999b. RXR-2, a member of the retinoid x receptor family in Schistosoma mansoni. Gene 233: 33-38.

Hanks SK, Quinn AM, Hunter T 1988. The protein kinase family: conserved features and deduced phylogeny of the catalytic domains. Science 241: 42-52.

Harari PM 2004. Epidermal growth factor receptor inhibition strategies in oncology. Endocr Relat Cancer 11: 689-708.

Heldin CH 1996. Protein tyrosine kinase receptors. Cancer Surv 27: 7-24.

Hubbard SR, Till JH 2000. Protein tyrosine kinase structure and function. Annu Rev Biochem 69: 373-398.

Inal JM 1999. Schistosoma TOR (trispanning orphan receptor), a novel, antigenic surface receptor of the blood-dwelling, Schistosoma parasite. Biochim Biophys Acta 1445: 283298.

Kampkotter A, Ridgers I, Johnston DA, Rollinson D, Kunz W, Grevelding CG 1999. Schistosoma mansoni: cloning and characterisation of the Ras homologue. Exp Parasitol 91: 280-283.

Kapp K, Knobloch J, Schussler P, Sroka S, Lammers R, Kunz W, Grevelding CG 2004. The Schistosoma mansoni Src kinase TK3 is expressed in the gonads and likely involved in cytoskeletal organization. Mol Biochem Parasitol 138: 171-182.

Kapp K, Schussler P, Kunz W, Grevelding CG 2001. Identification, isolation and characterisation of a Fyn-like tyrosine kinase from Schistosoma mansoni. Parasitology 122: 317327.

Knobloch J, Rossi A, Osman A, LoVerde PT, Klinkert MQ, Grevelding CG 2004. Cytological and biochemical evidence for a gonad-preferential interplay of SmFKBP12 and SmTbetaR-I in Schistosoma mansoni. Mol Biochem Parasitol 138: 227-236.

Knobloch J, Winnen R, Quack M, Kunz W, Grevelding CG 2002. A novel Syk-family tyrosine kinase from Schistosoma mansoni which is preferentially transcribed in reproductive organs. Gene 294: 87-97.

Kunz W 2001. Schistosome male-female interaction: induction of germ-cell differentiation. Trends Parasitol 17: 227-231.

Lantner F, Ziv E, Ram D, Schechter I 1998. Different forms of the mRNA encoding the heat-shock transcription factor are expressed during the life cycle of the parasitic helminth Schistosoma mansoni. Eur J Biochem 253: 390-398.

Machida K, Mayer BJ, Nollau P 2003. Profiling the global tyrosine phosphorylation state. Mol Cell Proteomics 2: 215-233.

Manning G, Plowman GD, Hunter T, Sudarsanam S 2002a. Evolution of protein kinase signalling from yeast to man. Trends Biochem Sci 27: 514-520.

Manning G, Whyte DB, Martinez R, Hunter T, Sudarsanam S $2002 \mathrm{~b}$. The protein kinase complement of the human genome. Science 298: 1912-1934.

McGonigle S, Beall MJ, Feeney EL, Pearce EJ 2001a. Conserved role for 14-3-3e downstream of type I TGFL receptors. FEBS Letters 490: 65-69.

McGonigle S, Beall MJ, Pearce EJ 2002. Eukaryotic initiation factor 2 alpha subunit associates with TGF beta receptors and 14-3-3 epsilon and acts as a modulator of the TGF beta response. Biochemistry 41: 579-587.

McGonigle S, Feeney EL, Beall MJ, Pearce EJ 2001b. SIP, a novel SH3 domain-containing protein, interacts with Schistosoma mansoni receptor kinase 1. Mol Biochem Parasitol 114: 119-123.

Milhon JL, Albert TJ, Vande Waa EA, O'Leary KA, Jackson RN, Kessler MA, Schuler LA, Tracy JW 2000. SmMAK16, the Schistosoma mansoni homologue of MAK16 from yeast, targets protein transport to the nucleolus. Mol Biochem Parasitol 108: 225-236.

Naula C, Parsons M, Mottram JC 2005. Protein kinases as drug targets in trypanosomes and Leishmania. Biochim Biophys Acta 30: 151-159.

Neet K, Hunter T 1996. Vertebrate non-receptor protein-tyrosine kinase families. Genes Cells 1: 147-169.

Oliveira G, Bahia D 2004. The genome of Schistosoma mansoni. Proc of the Third Braz Symp Math Comput Biol 1: 101-115.

Oliveira G, Rodrigues NB, Romanha AJ, Bahia D 2004. Genome and genomics of shistosomes. Can J Zool 82:375390.

Osman A, Niles EG, LoVerde PT 1999. Characterization of the Ras homologue of Schistosoma mansoni. Mol Biochem Parasitol 100: 27-41.

Osman A, Niles EG, LoVerde PT 2001. Identification and characterization of a Smad2 homologue from Schistosoma mansoni, a transforming growth factor-beta signal transducer. J Biol Chem 276: 10072-10082.

Osman A, Niles EG, LoVerde PT 2004. Expression of functional Schistosoma mansoni Smad4: role in Erk-mediated transforming growth factor beta (TGF-beta) down-regulation. J Biol Chem 279: 6474-6486.

Pellman D, Garber EA, Cross FR, Hanafusa H 1985. An Nterminal peptide from p60src can direct myristylation and plasma membrane localization when fused to heterologous proteins. Nature 314: 374-377.

Plowman GD, Sudarsanam S, Bingham J, Whyte D, Hunter T 1999. The protein kinases of Caenorhabditis elegans: a model for signal transduction in multicellular organisms. Proc Natl Acad Sci USA 96: 13603-13610.

Ramachandran H, Skelly PJ, Shoemaker CB 1996. The Schistosoma mansoni epidermal growth factor receptor homologue, SER, has tyrosine kinase activity and is localized in adult muscle. Mol Biochem Parasitol 83: 1-10.

Resh MD 1994. Myristylation and palmitylation of Src family members: the fats of the matter. Cell 76: 411-413.

Santos TM, Machado CR, Franco GR, Pena SD 2002. Characterization and comparative functional analysis in yeast of a Schistosoma mansoni Rho1 GTPase gene. Mol Biochem Parasitol 125: 103-112.

Schussler P, Grevelding CG, Kunz W 1997. Identification of Ras, MAP kinases, and a GAP protein in Schistosoma mansoni by immunoblotting and their putative involvement in male-female interaction. Parasitology 115: 629-634.

Shoemaker CB, Ramachandran H, Landa A, dos Reis MG, Stein LD 1992. Alternative splicing of the Schistosoma mansoni gene encoding a homologue of epidermal growth factor receptor. Mol Biochem Parasitol 53: 17-32. 
Siddiqui AA, Podesta RB, Clarke MW 1991. Schistosoma mansoni: characterization and identification of calcium-binding proteins associated with the apical plasma membrane and envelope. Exp Parasitol 72: 63-68.

Traxler P 2003. Tyrosine kinases as targets in cancer therapy successes and failures. Expert Opin Ther Targets 7: 215234.

Verjovski AS, Leite LC, Dias NE, Menck CF, Wilson RA 2004. Schistosome transcriptome: insights and perspectives for functional genomics. Trends Parasitol 20: 304-308.

Vermeire JJ, Osman A, LoVerde PT, Williams DL 2003. Characterization of a Rho homologue of Schistosoma mansoni. Int J Parasitol 33: 721-731.

Vicogne J, Cailliau K, Tulasne D, Browaeys E, Yan YT, Fafeur
V, Vilain JP, Legrand D, Trolet J, Dissous C 2004. Conservation of epidermal growth factor receptor function in the human parasitic helminth Schistosoma mansoni. J Biol Chem 279: 37407-37414.

Vicogne J, Pin JP, Lardans V, Capron M, Noel C, Dissous C 2003. An unusual receptor tyrosine kinase of Schistosoma mansoni contains a Venus Flytrap module. Mol Biochem Parasitol 126: 51-62.

Vieth M, Higgs RE, Robertson DH, Shapiro M, Gragg EA, Hemmerle H 2004. Kinomics-structural biology and chemogenomics of kinase inhibitors and targets. Biochim Biophys Acta 1697 (1-2): 243-257.

Yarden Y, Ullrich A 1988. Growth factor receptor tyrosine kinases. Annu Rev Biochem 57: 443-478. 
